\title{
Crónica del "Coloquio sobre transformaciones del Régimen Local" (Sevilla, 19 y 20 de abril de 2005)
}

\author{
Antonio José Sánchez Sàez \\ Profesor Ayudante de Derecho Administrativo \\ Universidad de Sevilla
}

Los días 19 y 20 de abril se celebró en Sevilla el "Coloquio sobre transformaciones del régimen local”, dirigido por D. Alfonso Pérez Moreno, Catedrático de Derecho Administrativo de la Universidad de Sevilla y Director de la Revista Andaluza de Administración Pública. Se desarrollaron tres sesiones en las que se adoptó un esquema de exposición basado en una breve introducción teórica realizada por un experto en la materia a la que seguían amplios tiempos dedicados a debatir las cuestiones planteadas. En las discusiones participaban tanto los integrantes de la mesa como los asistentes (en su mayoría Profesores de Universidad, funcionarios de la Administración Local y Secretarios de Ayuntamiento).

Salta a la vista la oportunidad del evento, tras haber visto la luz recientemente el Primer Borrador del Libro Blanco para la Reforma del Gobierno Local en España y en pleno proceso de descentralización de las competencias autonómicas a las Administraciones Locales.

La nota diferencial de este Coloquio en relación con otros de temática similar recientemente celebrados en otros lugares de España (Barcelona, Zaragoza, etc.) estuvo precisamente en la importante nómina de Secretarios de Ayuntamiento invitados por la Dirección de las Jornadas como ponentes. Se les dio voz, así, a los grandes olvidados de la reforma local en España, un cuerpo de funcionarios de alto nivel que tiene como penacho el saberse centro de la vida jurídica, social y política de los Ayuntamientos en España. A pesar de haber dado figuras muy relevantes para nuestro Derecho Administrativo, ha sido injustamente postergado tanto de la Comisión redactora del Libro Blanco como de los debates legislativos que dieron lugar al Pacto Local estatal. Entre otros, asistieron D. Venancio Gutiérrez Colomina, D. Valentín Merino Estrada, D. José Ignacio Soto Valle, D. Paulino Martín Hernández, D. Federico 
Romero Hernández, etc., Secretarios, respectivamente de los Ayuntamientos de Sevilla, Valladolid, Badalona, Madrid y Málaga.

Las Jornadas han sido auspiciadas por el Instituto Andaluz de Administración Pública (IAAP), y hay que decir, como curiosidad, que con el Coloquio se estrenaba el Salón de Actos de un magnífico Aulario recién construido para albergar la labor normativa que viene llevando a cabo con mucho éxito el Instituto, y que, hasta ahora, no tenía sede fija.

En el acto de inauguración D. Alfonso Pérez Moreno dio la bienvenida a todos los presentes, anunciando que todas las intervenciones serían grabadas para la realización posterior de un Libro de Actas. El Prof. Pérez Moreno presentó a su vez a D. Joaquín Castillo Sempere, Director del IAAP, quien se congratuló por la organización de las Jornadas. D. Francisco Toscano Sánchez, Alcalde de Dos Hermanas y Presidente de la Federación Andaluza de Municipios y Provincias, se encargó a continuación de recalcar la trascendencia del presente momento histórico, a pocos meses vista de la reforma de la LRBRL, firmado el Pacto Local estatal y en pleno proceso de plasmación de los autonómicos.

Y finalmente tomó la palabra la Excma. Sra. Dª . María José López González, Consejera de Justicia y Administración Pública, y relacionada ella misma con la vida local, ya que ejerció como concejal del Ayuntamiento de Granada durante varios años. Agradeció al Prof. Pérez Moreno la organización del Coloquio y se mostró interesada para tener en cuenta las conclusiones a las que se pudieran llegar.

Acabado el acto de inauguración, se alteró el orden de intervención de los ponentes, ya que D. LUCIANO PAREJO ALFONSO debía estar pronto en Madrid para asistir, en su calidad de Rector de la Universidad Menéndez Pelayo, recientemente estrenada, a un acto importante con presencia de los Reyes de España. El Catedrático de Derecho Administrativo de la Universidad Carlos III tituló su intervención "Descentralización, autonomía, subsidiariedad". Sus reflexiones gozaban de la autoridad añadida de ser pronunciadas por uno de los ponentes redactores del Libro Blanco, y, en, pocos minutos, repasó las cuestiones más candentes de la reforma del régimen local que se avecina. Entre ellas, la llamada "interiorización" del régimen local, o posibilidad de que las CC.AA. puedan asumir mayores competencias legislativas sobre la materia, presupuesto un adelgazamiento de las bases aprobadas por el Estado con base en el art. 149.1, 18 $\mathrm{CE}$. Se mostró favorable a un aumento de la porción autonómica del régimen local, pero recordando como límites a esa inte- 
riorización la existencia misma de las Provincias y Municipios, que no pueden ser proscritos de ningún Estatuto de Autonomía al estar acuñados en el art. 137 CE. Asimismo, frente a la tendencia que centra la "Administración única" en la escala autonómica hizo hincapié en que la Administración Local viene consagrada en nuestra Constitución como la Administración común, teniendo en cuenta el principio de distribución territorial del poder, el principio de subsidiariedad y el de descentralización.

Con ese panorama, en su opinión, al Estado sólo le cabría establecer las decisiones básicas sobre régimen local, dejando margen, con las cautelas señaladas, a la legislación local de las CC.AA. Se mostró partidario, además, por no integrar en esas bases estatales ni la garantía financiera ni una hipotética lista de competencias propias, como núcleo irrenunciable de su garantía institucional. Como avances deseables enumeró la necesidad de que las Administraciones superiores legislaran por objetivos, dejando margen de actuación a los entes locales; la flexibilización para las Corporaciones locales de la reserva de ley para las cuestiones que lo exijan y su sustitución o cobertura por parte del Reglamento orgánico local.

Sin solución de continuidad D. ALFONSO PÉREZ MORENO, Director de las Jornadas, alabó la brillante intervención de D. Luciano Parejo, e hizo frente a su vez a "La cuestión local pendiente", recorriendo los avatares históricos que, desde principios del siglo XX, con los proyectos legislativos de Maura, han dado con el sistema de régimen local actual. Por conocimiento propio, puso ejemplos palmarios de la constante depredación de competencias locales por parte del Estado y, sobre todo, de las CC.AA., y se mostró favorable a favor de una reforma de la LRBRL que incluyese una lista de competencias locales indisponibles para los Legisladores central y autonómicos. En alusión al Libro Blanco elogió el esfuerzo de síntesis jurisprudencial y jurídico realizado, pero se mostró precavido sobre la viabilidad de su aplicación a la realidad.

Tras una pausa obligada, el Prof. Pérez Moreno presentó al siguiente ponente, el Catedrático de Derecho Administrativo de la Universidad de Barcelona, D. TOMÁS FONT I LLOVET, uno de los máximos estudiosos españoles de la cuestión local. Director de los prestigiosos Anuarios del Gobierno Local, publicados por el Instituto de Derecho Público de Cataluña, sus investigaciones sobre la reforma del régimen local están teniendo un hondo impacto en los proyectos que se avecinan. Comenzó el Prof. Font por destacar la última y reciente reforma constitucional italiana a favor de la devolución de competencias a los Ayuntamientos, y sobre la integración de representantes del Gobier- 
no Local en el Senado, con voz pero sin voto. Se mostró, en cambio, desanimado ante la falta de voluntad política para trasladar esta opción a España.

El Prof. Font se decantó a favor de "interiorizar" el régimen local en la inminente reforma del Estatuto de Autonomía para Cataluña, argumentando en su apoyo las Recomendaciones del Consejo de Europa (como la n ${ }^{\circ}$. 121, sobre la aplicación de la Carta Europea de la Autonomía Local en España). Se mostró partidario, como Luciano Parejo, de flexibilizar la reserva de ley en materia de potestad sancionadora y tributaria. En su exposición se mostró muy equilibrado, considerando que los Estatutos de Autonomía deberían integrar, a modo de baluarte de la autonomía local, los siguientes elementos de contención:

- una garantía institucional de defensa frente al Legislador autonómico;

- la atribución a los entes locales de competencia "universal" sobre todas la materias de interés local, con base en el principio de subsidiariedad, en el marco de la ley;

- la previsión de que debería existir una atribución expresa de competencias a favor de las demás Administraciones cuando su ejercicio pudiere afectar a las competencias locales;

- un medio de control de la subsidiariedad por parte de los entes locales frente a la Comunidad Autónoma: serviría como anticipo a nivel estatal mantenía el ponente- con que el Senado pudiera pronunciarse expresamente sobre qué es básico y qué no en las Leyes que pudieran afectar a las competencias locales, esquema que podrían copiar la Asambleas Legislativas autonómicas, emitiendo un informe previo preceptivo (instrumento que ya existe en algunos Ländern alemanes o en el parlamento de Escocia, y que estaba previsto también en la reforma de la Constitución italiana de 2003).

El coloquio posterior a las tres intervenciones fue fructífero y largo.

Posteriormente intervino como ponente D. FEDERICO ROMERO HERNÁNDEZ, Secretario General del Ayto. de Málaga y Prof. Titular de Derecho Administrativo, quien expuso su opinión sobre las "Carencias y disfunciones en la estructura del Régimen Local”, señalando algunas incongruencias en las que, a su juicio, incurre la Ley 57/2003, de 16 de diciembre, de Medidas para la Modernización del Gobierno Local, con lo que se cerró, tras un nuevo tiempo de debate, la sesión matutina del Coloquio.

Por la tarde tomaron la palabra D. VALENTÍN MERINO ESTRADA, Secretario del Ayuntamiento de Valladolid, que habló sobre los "Modelos de 
competencias locales", al que siguió D. FRANCISCO SOSA WAGNER, Catedrático de Derecho Administrativo de la Universidad de León, autor de un reconocido Manual sobre Administración Local y de numerosas publicaciones sobre el tema. En una intervención titulada "Los Servicios Municipales", el Prof. Wagner se reveló muy escéptico con la mayor parte del Libro Blanco para la reforma del gobierno local, desglosando sus flaquezas y cotejando la audacia de sus avances con la piedra de toque clásica del "Selbstverwaltung" del Municipio alemán. Para aplacar la euforia de aquellos que defienden el tránsito de España hacia un Estado federal recomendó la lectura del Libro de THOMAS DARNSTÄDT “La trampa del consenso", recientemente publicado en la editorial Trotta del que ha sido traductor, en el que se relatan las desarmonías y aspectos menos agradables del federalismo alemán. Se abrió otro turno de debate en el que muchos Secretarios de Ayuntamientos secundaron las reticencias del Prof. SOSA sobre algunos extremos del Libro Blanco.

En el siguiente turno de palabra abrió fuego D. MANUEL DOMINGO ZABALLOS, Secretario de Ayuntamiento y, a la sazón, actual Magistrado del Tribunal Superior de Justicia de la Comunidad Valenciana. Su exposición versó sobre "La Provincias y otras alternativas de Administraciones supramunicipales", en la que se postuló contrario a las Comarcas y más favorable a otras técnicas de asociacionismo municipal. Finalizó la sesión vespertina del primer día el Prof. JOSÉ LUIS RIVERO YSERN, Catedrático de Derecho Administrativo de la Universidad de Sevilla, autor también de un reputado Manual sobre Régimen Local, tema al que ha dedicado otras muchas publicaciones. Habló sobre la "Organización de las Entidades Locales". Tras un turno de debate muy intenso se dio por acabada la primera jornada del Coloquio.

A la mañana siguiente fue el turno de D. JOSÉ IGNACIO SOTO VALLE, Presidente del Colegio de Secretarios, Interventores y Tesoreros de Barcelona y Secretario también del Ayuntamiento de Badalona, uno de los mayores en población de Cataluña después de las capitales de Provincia. Su intervención se tituló "La función pública y la función directiva local", y, a lo largo de ella, expuso de manera concienzuda los modelos municipales comparados de otros países de Europa en los que se han introducido ciertas notas de administración gerencial no burocrática, a la que el Estado æ dijo æ no debería tener miedo.

Posteriormente, D. PAULINO MARTÍN HERNÁNDEZ, Secretario del Ayuntamiento de Madrid, disertó sobre "Las diferencias de las Grandes Ciudades", y se mostró muy agradecido por poder salir de la rutina y volver a las funciones pedagógicas en este Foro. Desgranó con exhaustividad todos los en- 
tresijos de las nuevas exigencias que Ley de Medidas para la Modernización del Gobierno Local impone a las "grandes ciudades", en la que vio más sombras que claros.

Tras otro coloquio muy distendido, le dio réplica D. VENANCIO GUTIÉRREZ COLOMINA, Secretario General del Ayuntamiento de Sevilla, quien habló de la "Institucionalización de la dimensión metropolitana", poniendo al auditorio al corriente del complejo engarce de los planes subregionales de ordenación del territorio andaluces sobre áreas metropolitanas con la Ley de Medidas para la Modernización del Gobierno Local y con las diferentes técnicas para interrelacionar los Municipios que se integren en Áreas Metropolitanas de facto, postulándose favorablemente al empleo de los consorcios y conciertos, por su flexibilidad. Nuevo coloquio.

La última intervención corrió a cargo de D. ÁNGEL MENÉNDEZ REXACH, Catedrático de Derecho Administrativo de la Universidad Autónoma de Madrid, a quien se le encomendó reflexionar sobre la "Función urbanística de las Entidades Locales", caso testigo de la severa coordinación en la que se ven inmersas las Administraciones Locales cuando ejercen competencias concurrentes con las demás Administraciones. De manera muy amena relató las experiencias suscitadas en la Comunidad Autónoma de Madrid y, para acabar, se confesó a favor de que las grandes ciudades puedan aprobar definitivamente los planes de urbanismo y que tuvieran un papel más decisivo en la elaboración de los planes de ordenación del territorio o de medio ambiente autonómicos.

La clausura corrió a cargo de D. Alfonso Pérez Moreno, que se felicitó por el elevado nivel de todas las ponencias, la viveza de los debates y la cálida acogida de los asistentes por parte del IAAP. Avanzó una vez más que las Jornadas serían plasmadas dentro de poco tiempo en un Libro de Actas, que está por salir. 